Journal of Experimental and Clinical Medicine https://dergipark.org.tr/omujecm

Research Article

$\mathrm{J}$ Exp Clin Med

2021; 38(3): 288-293

doi: $10.52142 /$ omujecm.38.3.15

\title{
Nonsynonymous variations of ion channel-related genes as risk factors in epilepsy
}

\author{
Burcu BİTERGE SÜT ${ }^{1, *(i)}$, Hayriye SOYTÜRK ${ }^{2}$ (i) \\ ${ }^{1}$ Department of Medical Biology, Faculty of Medicine, Niğde Ömer Halisdemir University, Niğde, Turkey \\ ${ }^{2}$ Faculty of Agriculture, Bolu Abant İzzet Baysal University, Bolu, Turkey
}

\begin{abstract}
\begin{tabular}{ccccc}
\hline Received: 24.12 .2020 & $\bullet$ & Accepted/Published Online: 01.02 .2021 & Final Version: 23.04 .2021 \\
\hline
\end{tabular}
Abstract

Recurrent seizures are characteristic to epilepsy, which often arise due to increased electrical activity. Ligand-gated ion channels are considered as key factors in epilepsy as they regulate and maintain neuronal membrane potential via regulating ion transportation. Therefore, this study aims to identify ion channel-related single nucleotide variations that are considered as risk factors in epilepsy and determine their potential effects on pathogenicity, protein stability and structure using in silico methods. For this purpose, ion channel-related mutations linked with epilepsy were retrieved from ClinVar. Pathogenicity scores and protein stability were predicted using FATHMM-XF and MUpro, respectively. Structural alterations were determined via HOPE server. We identified 17 epilepsy-related missense mutations, 11 of which were in ion channel-related genes. Nonsynonymous substitutions of p.E177A, p.D219N, p.A322D, p.R577Q, p.E282K, p.V831M and p.R1072C were determined as pathogenic, while all mutations resulted in varying degrees of decrease in overall protein stability. Furthermore, all variants were annotated with risk for disease and introduction of distinct side chains caused differences in size, charge and hydrophobicity, as well as contact with other proteins and ligands. In conclusion, mutations in ion channel-related genes were previously identified in several genetic association studies while their functional annotations were not addressed. The results of this study provide a functional explanation to the pathogenic effects of ion channelrelated gene mutations that are considered as risk factors in epilepsy.
\end{abstract}

Keywords: ion channels, missense mutation, epilepsy, risk factor

\section{Introduction}

Epilepsy is a major neurological disease affecting millions worldwide. It is characterized by recurrent and unprovoked seizures that can cause loss of consciousness or abnormal motor behavior depending on the affected brain region (Stafstrom and Carmant, 2015.). The diagnosis begins with seizure type(s) and can then be defined as focal, generalized, combined focal and generalized or unknown epilepsy when sufficient electroclinical information is available (Fisher, 2017; Scheffer et al., 2017). A seizure is defined as an increase in electrical activity in the brain that can be triggered by various factors such as medications (Chen et al., 2016), metabolic changes (Imad et al., 2015) and infections (Zoons et al., 2008). When seizures emerge spontaneously, they are considered epileptic. The main mechanism that triggers epilepsy is the shift of the balance between excitation and inhibition towards the excitation side. In the central nervous system, there are two important paths that mediate this mechanism. The first is the formation of action potential in neurons and its transmission with axonal conduction. Here, voltage-gated sodium and potassium channels play a significant role. The second one is synapses, in which ligand-gated ion channels such as nicotinic acetylcholine receptor (nAChR) channel, GABA and glycine receptor channels, serotonin and glutamate receptor channels are important. Calcium channels, which allow neurotransmitter vesicles to flow into the synaptic space, also play a role. Mutations in these channels cause a change in the neuronal membrane potential, contributing to the disruption of the balance between excitation and inhibition. As a result, epileptic seizures and even epileptogenesis occur (Armijo et al., 2005).

GABAA-mediated inhibition basically affects postsynaptically located GABAA receptors such as GABRD and GABRA1, through GABA release from synaptic vesicles. In the mature central nervous system, it causes chloride ion $\left[\mathrm{Cl}^{-}\right.$ ] influx and an inhibitory postsynaptic potential. Transient receptor activation with high concentrations of GABA at the synapse is called phasic inhibition. Tonic inhibition refers to the condition in which GABA can move away from the synapse at low concentrations in a spatially and temporally constrained GABAA-mediated inhibition (Farrant and Nusser, 2005). CLCN2 encodes the voltage-gated chlorine channel $\mathrm{ClC}-2$ and is expressed in neurons that are postsynaptic to GABAergic inhibitory synapses. Maintenance of low intracellular chloride concentration by CIC-2 is essential for 
the inhibitory response to GABA (Kearney and Meisler, 2009). CACNA1H serves as a member of the T-type calcium channel family. SLC12A5 gene codes for the $\mathrm{K}^{+} / \mathrm{Cl}^{-}$co-transporter 2 (KCC2), which is the main $\mathrm{Cl}^{-}$extruder of neurons and functions as a suitable inhibitor for the neurotransmitters $\gamma$ aminobutyric acid (GABA) and glycine (Saito et al., 2017). Myoclonin1/EFHC1 is a newly identified microtubule associated protein (MAP) that directly interacts with $\alpha$-tubulin via the microtubule binding domain located at the $\mathrm{N}$-terminus. EFHC1 acts as a non-ion channel gene, which encodes a protein that contains a $\mathrm{Ca}^{2+}$-binding EF-hand motif, and overexpression of Myoclonin1/EFHC1 induces in vitro neuronal and synaptic apoptosis by increasing R-type voltagedependent $\mathrm{Ca}^{2+}$ channel currents (de Nijs et al., 2009).

Due to their significant roles in the regulating neuronal membrane potential, ion channels have been a center of attention in the field of neurology. In line with this, several studies in the literature have implicated missense mutations of the voltage-gated chlorine channel encoding CLCN2 gene (Kearney and Meisler, 2009), calcium channel CACNA1H (Heron et al., 2007a), GABAA receptor subunits (Ishii et al., 2017; Niturad et al., 2017), the neuron-specific type $2 \mathrm{~K}^{+} / \mathrm{Cl}^{-}$ co-transporter KCC2 encoded by SLC12A5 (Saito et al., 2017) as well as the non-ion channel gene EFHC1 (Bailey et al., 2017) in epilepsy. Therefore, here in this study, we adopted an in silico-based approach to identify ion channel-related single nucleotide variations that are considered as risk factors in epilepsy and determine their potential effects on pathogenicity, protein stability and structure.

\section{Methods}

\subsection{Identification of mutations}

Ion channel-related mutations that are considered as risk factors in epilepsy are retrieved from the National Center for Biotechnology Information (https:/www.ncbi.nlm.nih.gov/clinvar/variation/). ClinVar is a repository of public data regarding associations between genetic variations and human phenotypes based on supporting evidence. The parameters used to identify ion channel-related mutations are depicted in Fig. 1. (ClinVar accession numbers: VCV000016212.2, VCV000127232.1, VCV000016214.1, VCV000009039.1， VCV000002701.1， VCV000002702.1, VCV000002703.1， VCV000218378.1， VCV000002068.1, VCV000002066.1 and VCV000002069.1).

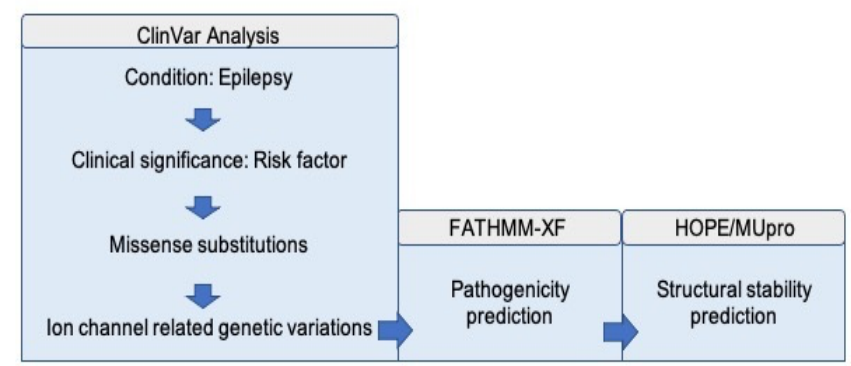

Fig. 1. Flow chart summarizing the methodological approach in the present study

\subsection{Prediction of pathogenicity}

To determine whether the ion channel-related mutations linked with epilepsy had any deleterious effects, pathogenicity scores were predicted using FATHMM-XF (http://fathmm.biocompute.org.uk/fathmm-xf/index.html) (Rogers et al., 2018). P-values (pathogenicity scores) obtained via FATHMM-XF ranges between $0-1$ and values above 0.5 are interpreted as deleterious/pathogenic. FATHMM-XF analysis was run using genomic locations of the mutations (in accordance with genome assembly GRCh38/hg38), which were obtained from ClinVar.

\subsection{Analysis of protein stability and structure}

Amino acid sequences for the full-length proteins were retrieved from UniProt (GABRD (ID: O14764), GABRA1 (ID: P51788), CLCN2 (ID: P14867), CACNA1H (ID: Q5JVL4), SLC12A5 (ID: O95180), EFHC1 (ID: Q9H2X9)). When more than one isoform was available, the longest isoform, which was chosen as the canonical sequence, was preferred. Analysis of protein stability in relation to the missense amino acid substitutions was performed using MUpro, which is a tool for protein stability prediction (http://mupro.proteomics.ics.uci.edu) (Cheng et al., 2006).

Structural alterations due to identified pathogenic mutations were determined via HOPE server (https://www3.cmbi.umcn.nl/hope) (Venselaar et al., 2010) using amino acid sequences obtained from UniProt.

\section{Results}

\subsection{Ion channel mutations as risk factors for epilepsy}

ClinVar revealed 23977 genetic variations in total including but not limited to frameshift, missense and nonsense mutations, deletions, duplications and insertions. The majority of these variations originated from germline mutations $(n=21935)$, while the others were either de novo $(n=1053)$ or somatic $(n=48)$. Among them, 26 variations were attributed clinical significance as risk factors. We further narrowed down the list of epilepsy-related genetic variations by missense mutations, which returned 17 results in GABRD, SLC2A1, CLCN2, GABRA1, EFHC1, CILK1, PDX1, CACNA1H and SLC12A5 genes. SLC2A1 is a glucose transporter, CILK1 is an intestinal serine/threonine kinase and PDX1 functions as a pancreatic nuclear factor; therefore, we omitted them in further analyses and focused on the ion channel-related GABRD, CLCN2, GABRA1, EFHC1, CACNA1H and SLC12A5 genes.

We identified 11 missense mutations (Table 1) within these ion channel-related genes that were implicated as risk factors for epilepsy. All of the identified nucleotide variations were associated with different subtypes of epilepsy with distinct seizure properties and/or affected age groups. Specifically, SLC12A5 R1072C substitution and EFHC1 I174V and C259Y substitutions were linked with susceptibility to IGE and JAE (juvenile absence epilepsy), respectively. 
Table 1. Ion channel gene variations analyzed in this study

\begin{tabular}{|c|c|c|c|c|}
\hline Gene name & Function & AA substitution & Condition & Reference \\
\hline$G A B R D$ & $\begin{array}{c}\text { Ligand-gated chloride channel } \\
\text { inhibitor }\end{array}$ & E177A & $\begin{array}{l}\text { Generalized epilepsy with } \\
\text { febrile seizures plus }\end{array}$ & Dibbens et al., 2004 \\
\hline GABRA1 & $\begin{array}{l}\text { Ligand-gated chloride channel } \\
\text { inhibitor }\end{array}$ & D219N, A322D & Epilepsy, juvenile myoclonic & $\begin{array}{l}\text { Lachance-Touchette et } \\
\text { al., 2011; Ding et al., } \\
2010\end{array}$ \\
\hline CLCN2 & Voltage-gated chloride channel & R577Q & $\begin{array}{l}\text { Epilepsy with grand mal } \\
\text { seizures on awakening }\end{array}$ & Saint-Martin et al., 2009 \\
\hline CACNAIH & $\begin{array}{l}\text { Voltage-dependent calcium } \\
\text { channel complex protein }\end{array}$ & $\begin{array}{l}\text { F161L, E282K, } \\
\text { V831M }\end{array}$ & Epilepsy, childhood absence & Chen et al., 2003 \\
\hline SLC12A5 & Potassium/chloride transporter & R1072C & $\begin{array}{c}\text { Epilepsy, idiopathic } \\
\text { generalized (susceptibility to) }\end{array}$ & Kahle et al., 2014 \\
\hline \multirow[t]{2}{*}{ EFHC1 } & \multirow[t]{2}{*}{ Calcium ion binding protein } & $\mathrm{I} 174 \mathrm{~V}, \mathrm{C} 259 \mathrm{Y}$ & $\begin{array}{l}\text { Epilepsy, juvenile absence } \\
\text { (susceptibility to) }\end{array}$ & Stogmann et al., 2006 \\
\hline & & $\mathrm{D} 253 \mathrm{Y}$ & Myoclonic epilepsy, juvenile & Suzuki et al., 2004 \\
\hline
\end{tabular}

Table 2. In silico analysis of pathogenicity and protein stability for the selected ion channel mutations

\begin{tabular}{|c|c|c|c|c|c|c|c|}
\hline \multirow[b]{2}{*}{ Gene name } & \multirow[b]{2}{*}{ AA change } & \multirow[b]{2}{*}{ dbSNP ID } & \multirow[b]{2}{*}{$\begin{array}{c}\text { Allele } \\
\text { frequency }\end{array}$} & \multicolumn{2}{|c|}{ Pathogenicity } & \multicolumn{2}{|c|}{ Protein Stability } \\
\hline & & & & Prediction & Score & Prediction & $\Delta \Delta \mathrm{G}$ \\
\hline$G A B R D$ & p.E177A & rs 121434580 & $\mathrm{n} / \mathrm{a}$ & Pathogenic & 0.757931 & Decrease & -0.23182591 \\
\hline GABRA1 & p.D219N & rs587777364 & $\mathrm{n} / \mathrm{a}$ & Pathogenic & 0.929361 & Decrease & -1.1316196 \\
\hline GABRAI & p.A322D & rs121434579 & $\mathrm{n} / \mathrm{a}$ & Pathogenic & 0.941727 & Decrease & -0.76389212 \\
\hline CLCN2 & p.R577Q & rs 137852682 & $3.13 \mathrm{e}^{-4}$ & Pathogenic & 0.879425 & Decrease & -0.78638535 \\
\hline CACNAIH & p.F161L & rs119454947 & $8.81 \mathrm{e}^{-6}$ & Benign & 0.095123 & Decrease & -0.57233831 \\
\hline CACNAIH & p.E282K & rs119454948 & $1.69 \mathrm{e}^{-5}$ & Pathogenic & 0.924846 & Decrease & -0.73848501 \\
\hline CACNAIH & p.V831M & rs119454949 & $1.43 \mathrm{e}^{-5}$ & Pathogenic & 0.916787 & Decrease & -1.879213 \\
\hline$S L C 12 A 5$ & p.R1072C & rs548424453 & $4.95 \mathrm{e}^{-5}$ & Pathogenic & 0.745658 & Decrease & -1.0625526 \\
\hline EFHCl & p.I174V & rs 137852779 & $3.98 \mathrm{e}^{-6}$ & Benign & 0.171890 & Decrease & -0.97574957 \\
\hline EFHCl & p.C259Y & rs 137852780 & $\mathrm{n} / \mathrm{a}$ & Benign & 0.180000 & Decrease & -1.0762814 \\
\hline EFHC1 & p.D253Y & rs 137852778 & $1.99 \mathrm{e}^{-5}$ & Benign & 0.416226 & Decrease & -0.52608728 \\
\hline
\end{tabular}

\subsection{Determination of deleterious mutations}

The potential outcomes of ion channel-related missense mutations were predicted using FATHMM-XF, which identified seven mutations, namely p.E177A, p.D219N, p.A322D, p.R577Q, p.E282K, p.V831M and p.R1072C as pathogenic (pathogenicity score $>0.5$ ) (Table 2). All missense substitutions of the EFHC1 gene (p.I174V, p.C259Y, p.D253Y) were predicted as benign, along with CACNA1H mutation p.F161L. Pathogenicity scores closer to 1 indicate higher confidence and accuracy; thus, substitutions of p.D219N, p.A322D, p.E282K and p.V831M were identified as the most confident and accurate deleterious mutations ( $p$ values above 0.9 ).

\subsection{Structural effects}

In order to evaluate the potential outcomes of these pathogenic mutations on protein structure and function, we performed protein stability prediction via MUpro and determined the structural changes induced by a single amino acid substitution at the tertiary (3D) level using the HOPE server. Analysis of protein stability in relation to the missense amino acid substitutions using MUpro showed that all mutations resulted in varying degrees of decrease in overall protein stability (Table 2). Lower $\Delta \Delta \mathrm{G}$ values implicate a greater decrease in protein stability, pointing towards GABRA1 p.D219N, CACNA1H p.V831M and EFHC1 p.C259Y mutations as the top three most destabilizing mutations. Single nucleotide variations resulting in missense substitutions often cause alterations within the overall protein structure. Results of the HOPE server analysis showed that all variants were annotated with risk for disease. The pathogenic ion channel mutations introduced distinct side chains (Fig. 2), causing differences in size, charge, and hydrophobicity, as well as contact with other proteins and ligands. Specifically, E177A substitution resulted in a smaller and more hydrophobic residue with a neutral charge, while the wild type residue had a negative charge. Similarly, the negative charge of the wild type residue was neutralized by the D219N substitution. A322D mutation led to a less hydrophobic residue with a negative charge, as opposed to the neutral wild type residue. The loss of hydrophobicity was predicted to affect the interactions between the GABRA1 protein and the membrane lipids. 

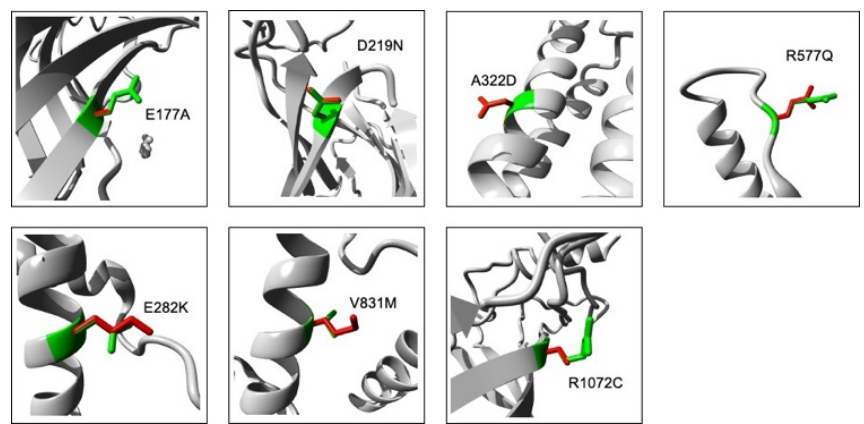

Fig. 2. Structural alterations of the 3D organization resulting from ion channel-related pathogenic missense mutations p.E177A, p.D219N, p.A322D, p.R577Q, p.E282K, p.V831M and p.R1072C. Wild-type amino acids are indicated in green, while mutated amino acids are shown in red

Substitutions of R577Q and R1072C caused the neutralization of the positive charge of the wild type residue. E282K caused the most drastic negative to positive charge difference, which could potentially result in repulsion of other residues in the protein or its ligands. A322D, E282K and V831M introduced larger amino acid side chains into the protein, which were predicted to lead to structural bumps. Furthermore, structural predictions identified E177A, A322D, R577Q and V831M substitutions as damaging as their wild type counterparts were highly conserved.

\section{Discussion}

Only one third of all epilepsy patients share a medical condition that causes epilepsy such as head trauma, stroke or tumor; of which $70 \%$ are diagnosed with idiopathic epilepsy via electrophysiological methods (Gardiner, 2005). On the other hand, genetic factors are considered as more dominant determinants in epilepsy patients. Several subtypes of idiopathic epilepsy emerge with multi-factorial reasons such as the monogenic autosomal dominant idiopathic generalized epilepsy (IGE), certain focal epilepsies and generalized epilepsy with febrile seizures plus (GEFS+), while monogenic epilepsy predominantly occurs with single gene defects (Heron et al., 2007b; Scheffer et al., 2017). One such group of genes that are implicated in familial human epilepsy includes genes encoding for subunits of nicotinic acetylcholine receptors (nAChR), chlorine channel, GABAA receptors, potassium channels, sodium channels and calcium channels. For instance, Genetic epilepsy syndrome (GES) is associated with the mutations in synaptic proteins, which involve neurotransmitter receptors and voltage-gated ion channels creating an abnormal thalamocortical excitability leading to chronic seizures. Monogenetic mutations in GES are generally associated with ion channel mutations (Heyne et al., 2018). In line with the previous work in the literature suggesting significant roles for ion channelopathies in epilepsy, here we identified ion channel-related mutations that are considered as risk factors and determined their potential effects on pathogenicity, protein stability and structure. Our in-silico analysis has identified mutations in GABRD, GABRA1, CLCN2, CACNA1H, SLC12A5 and EFHC1 genes as potential risk factors for epilepsy. GABRD and GABRA1 are receptor subunits of GABAA, which acts as an important inhibitor of postsynaptic potential by enabling $\mathrm{Cl}^{-}$influx. Mutations in the receptor subunits of GABAA often results in the removal this inhibition and causes epileptic discharges. Previous studies have

identified single nucleotide variations in several genes encoding GABAA receptors. In particular, E177A mutation was shown to alter cell surface expression and single-channel gating properties of GABRD and was proposed as a susceptibility factor for GEFS+ and JME (Feng et al., 2006). Similarly, A322D and D219N mutations were reported to change gating kinetic properties of GABRA1 (LachanceTouchette et al., 2011). Moreover, A322D affected GABAergic bouton and dendritic spine formation as well as miniature inhibitory postsynaptic current amplitude in pyramidal neurons, while D219N did not (Ding et al., 2010; Lachance-Touchette et al., 2014).

Voltage-gated chlorine channel ClC-2 is encoded by CLCN2 gene, which is associated with several IGE subtypes including JME, CAE and EGMA (grand mal epilepsy) (Gardiner, 2005). Mutations in CLCN2 were shown to result in reduced $\mathrm{ClC}-2$ activity and overstimulation of postsynaptic cells at GABAergic synapses, which might lead to epileptic seizures (Kearney and Meisler, 2009). In vitro studies using recombinant $\mathrm{ClC} 2$ channels suggested a loss-of-function role for R577Q and showed that it causes deactivation of the voltage-gated chlorine channel (Saint-Martin et al., 2009). Intracellular $\left[\mathrm{Cl}^{-}\right]$concentration is mainly regulated by the $\mathrm{K}^{+} / \mathrm{Cl}^{-}$co-transporter $\mathrm{KCC} 2$, which is encoded by SLC12A5. Disruptions in $\left[\mathrm{Cl}^{-}\right]$homeostasis, possibly due to $\mathrm{KCC} 2$ dysfunction, are implicated in the pathogenesis of common neurodevelopmental disorders including mental disability, autism spectrum disorder, schizophrenia and epilepsy (Bozzi et al., 2012). Therefore, variants of SLC12A5 can potentially be pathogenic for neurological and psychiatric disorders by interfering with the excitation-inhibition balance. In support of this, studies identified SLC12A5 variants as risk factors for seizure disorders, detected pathogenic SLC12A5 variants in patients with neurodevelopmental diseases (Merner et al., 2015) and studies on human genetics associated mutations in KCC2 with the development of epilepsy (Saito et al., 2017).

JME is a lifelong disease, comprises $3-30 \%$ of all epilepsies and has no definitive treatment. EFHC1 variants are the most common mutations observed in hereditary myoclonic and grand mal clonic-tonic-clonic convulsions of JME (Bailey et al., 2017). Myoclonin $1 / \mathrm{EFHC} 1$ is actually a microtubuleassociated protein involved in the regulation of cell division and it affects neuroblast migration and synapse/dendrite formation (Grisar et al., 2012). Impairment of EFHC1 in rats was shown to disrupt the radial migration of projection nodes by affecting the development of the neocortex through ex vivo and utero electroporation, the mitosis and cell cycle output of cortical progenitors, radial glial structure (scaffold) 
organization and the movement of postmitotic neurons (de Nijs et al., 2009). Furthermore, EFHC1 mutations were associated with increased sensitivity to myoclonic and grand mal seizures and disruption of apoptosis in neurons/synapses where R-type voltage-dependent calcium channel function changes (Grisar et al., 2012). The calcium channel CACNA1H was first defined in the "Genetic Absence Epilepsy Rats of Strasbourg" model, which exhibited increased T-type currents with age and reflected the temporal profile of epilepsy development (Rajakulendran and Hanna, 2016). Mutations in CACNA1H were identified in patients with IGE and CAE, and changes in canal function similar to those due to CAE-related mutations were observed (Chen et al., 2003; Heron et al., 2007a). F161L, E282K and V831M mutations in CACNA1H were reported to cause shifts in membrane polarization and activation potentials (Khosravani et al., 2004). Among these mutations, V831M that we characterized as pathogenic, had a more significant effect. Overall, these results suggest that, in humans, CACNA1H might increase neuronal firing by decreasing the threshold value in neurons, thus leading to overstimulation. However, the role of CACNA1H in epilepsy has been controversial as no seizures were observed in CACNA1H knockout mice (Chen et al., 2003). Likewise, the ClinGen study group recently classified CACNA1H as a controversial gene and claimed that it provides poor genetic support in terms of clinical value (Helbig et al., 2018).

In conclusion, it is clear that ion channels and other related genes are key factors in epilepsy due to their critical importance for the regulation and maintenance of neuronal membrane potential via controlling ion transportation. Although single nucleotide variations of these genes have been widely studied, previous works have mainly consisted of genetic association studies and lacked establishment of functional links. In this paper, we identified a short-list of nonsynonymous mutations in ion channel-related genes, some of which were previously addressed by others in the context of epilepsy while the rest were analyzed for the first time in this study. Furthermore, we determined their potential effects of on pathogenicity, protein stability and structure and provided a functional explanation to the pathogenic effects of these mutations that were observed previously in genetic association studies.

\section{Conflict of interest}

The authors declare no financial or non-financial conflict of interest.

\section{Acknowledgments}

The authors would like to thank Cansu ÖNAL for helping with manuscript preparation.

\section{References}

1. Armijo, J.A., Shushtarian, M., Valdizan, E.M., et al. 2005. Ion channels and epilepsy. Curr. Pharm. Des. 11(15), 1975-2003.

2. Bailey, J.N., Patterson, C., de Nijs, L., Durón, R.M., Nguyen, V.H., Tanaka, M., Medina, M.T., Jara-Prado, A., Martínez-Juárez, I.E., Ochoa, A., Molina, Y., Suzuki, T., Alonso, M.E., Wight, J.E.,
Lin, Y.C., Guilhoto, L., Targas Yacubian, E.M., Machado-Salas, J., Daga, A., Yamakawa, K., Grisar, T.M., Lakaye, B., DelgadoEscueta, A.V., 2017. EFHC1 variants in juvenile myoclonic epilepsy: reanalysis according to NHGRI and ACMG guidelines for assigning disease causality. Genet. Med. 19(2),144-156.

3. Bozzi, Y., Casarosa, S., Caleo, M., 2012. Epilepsy as a neurodevelopmental disorder. Front. Psychiatry. 3,19.

4. Chen, Y., Lu, J., Pan, H., Zhang, Y., Wu, H., Xu, K., Liu, X., Jiang, Y., Bao, X., Yao, Z., Ding, K., Lo, W.H., Qiang, B., Chan, P., Shen, Y., Wu, X., 2003. Association between genetic variation of CACNA1H and childhood absence epilepsy. Ann. Neurol. 54(2), 239-243.

5. Chen, Z., Lusicic, A., O'Brien, T.J., Velakoulis, D., Adams, S.J., Kwan, P., 2016. Psychotic disorders induced by antiepileptic drugs in people with epilepsy. Brain. 139(10), 2668-2678.

6. Cheng, J., Randall, A., Baldi, P., 2006. Prediction of protein stability changes for single-site mutations using support vector machines. Proteins. 62(4),1125-32.

7. de Nijs, L., Léon, C., Nguyen, L., Loturco, J.J., Delgado-Escueta, A.V., Grisar, T., Lakaye, B., 2009. EFHC1 interacts with microtubules to regulate cell division and cortical development. Nat. Neurosci. 12(10), 1266-1274.

8. Dibbens, L.M., Feng, H.J., Richards, M.C., Harkin, L.A., Hodgson, B.L., Scott, D., Jenkins, M., Petrou, S., Sutherland, G.R., Scheffer, I.E., Berkovic, S.F., Macdonald, R.L., Mulley, J.C., 2004. GABRD encoding a protein for extra- or peri-synaptic GABAA receptors is a susceptibility locus for generalized epilepsies. Hum. Mol. Genet. 13(13), 1315-1319.

9. Ding, L., Feng, H.J., Macdonald, R.L., Botzolakis, E.J., Hu, N., Gallagher, M.J. 2010. GABA(A) receptor alpha1 subunit mutation A322D associated with autosomal dominant juvenile myoclonic epilepsy reduces the expression and alters the composition of wild type GABA(A) receptors. J. Biol. Chem. 285(34), 26390-26405.

10. Farrant, M., Nusser, Z., 2005. Variations on an inhibitory theme: phasic and tonic activation of $\operatorname{GABA}(\mathrm{A})$ receptors. Nat. Rev. Neurosci. 6(3), 215-229.

11. Feng, H.J., Kang, J.Q., Song, L., Dibbens, L., Mulley, J., Macdonald, R.L., 2006. Delta subunit susceptibility variants E177A and R220H associated with complex epilepsy alter channel gating and surface expression of alpha4beta2delta GABAA receptors. J. Neurosci. 26(5), 1499-1506.

12. Fisher, R.S., 2017. The new classification of seizures by the international league against epilepsy. Curr. Neurol. Neurosci. Rep. 17,48 .

13. Gardiner, M., 2005. Genetics of idiopathic generalized epilepsies. Epilepsia. 46(9), 15-20.

14. Grisar, T., Lakaye, B., de Nijs, L., LoTurco, J., Daga, A., DelgadoEscueta, A.V., 2012. Myoclonin1/EFHC1 in cell division, neuroblast migration, synapse/dendrite formation in juvenile myoclonic epilepsy. In: Noebels JL, Avoli M, Rogawski MA, Olsen RW, Delgado-Escueta AV, eds. Jasper's Basic Mechanisms of the Epilepsies. $4^{\text {th }}$ ed. Bethesda (MD): National Center for Biotechnology Information (US).

15. Helbig, I., Riggs, E.R., Barry, C.A., Klein, K.M., Dyment, D., Thaxton, C., Sadikovic, B., Sands, T.T., Wagnon, J.L., Liaquat, K., Cilio, M.R., Mirzaa, G., Park, K., Axeen, E., Butler, E., Bardakjian, T.M., Striano, P., Poduri, A., Siegert, R.K., Grant, A.R., Helbig, K.L., Mefford, H.C., 2018. The ClinGen Epilepsy Gene Curation Expert Panel-Bridging the divide between clinical domain knowledge and formal gene curation criteria. Hum. Mutat. 39(11), 1476-1484.

16. Heron, S.E., Khosravani, H., Varela, D., Bladen, C., Williams, 
T.C., Newman, M.R., Scheffer, I.E., Berkovic, S.F., Mulley, J.C., Zamponi GW. 2007a. Extended spectrum of idiopathic generalized epilepsies associated with $\mathrm{CACNA} 1 \mathrm{H}$ functional variants. Ann. Neurol. 62(6), 560-568.

17. Heron, S.E., Scheffer, I.E., Berkovic, S.F., Dibbens, L.M., Mulley, J.C., 2007b. Channelopathies in idiopathic epilepsy. Neurotherapeutics. 4(2), 295-304.

18. Heyne, H.O., Singh, T., Stamberger, H., Abou Jamra, R., Caglayan, H., Craiu, D., De Jonghe, P., Guerrini, R., Helbig, K.L., Koeleman, B.P.C., Kosmicki, J.A., Linnankivi, T., May, P., Muhle, H., Møller, R.S., Neubauer, B.A., Palotie, A., Pendziwiat, M., Striano, P., Tang, S., Wu, S., EuroEPINOMICS RES Consortium, Poduri, A., Weber, Y.G., Weckhuysen, S., Sisodiya, S.M., Daly, M.J., Helbig, I., Lal, D., Lemke, J.R., 2018. De novo variants in neurodevelopmental disorders with epilepsy. Nat. Genet. 50(7), 1048-1053.

19. Imad, H., Zelano, J., Kumlien, E. 2015. Hypoglycemia and risk of seizures: A retrospective cross-sectional study. Seizure. 25, 147-149.

20. Ishii, A., Kang, J.Q., Schornak, C.C., Hernandez, C.C., Shen, W., Watkins, J.C., Macdonald, R.L., Hirose, S., 2017. A de novo missense mutation of GABRB2 causes early myoclonic encephalopathy. J. Med. Genet. 54(3), 202-211.

21. Kahle, K.T., Merner, N.D., Friedel, P., Silayeva, L., Liang, B., Khanna, A., Shang, Y., Lachance-Touchette, P., Bourassa, C., Levert, A., Dion, P.A., Walcott, B., Spiegelman, D., DionneLaporte, A., Hodgkinson, A., Awadalla, P., Nikbakht, H., Majewski, J., Cossette, P., Deeb, T., Moss, S.J., Medina, I., Rouleau, G.A. 2014. Genetically encoded impairment of neuronal KCC2 cotransporter function in human idiopathic generalized epilepsy. EMBO Rep. 15(7), 766-774.

22. Kearney, J., Meisler, M., 2009. Single Gene Mutations in Inherited and Sporadic Epilepsy. In: Encyclopedia of Basic Epilepsy Research. Elsevier/Academic Press, London. 369-374.

23. Khosravani, H., Altier, C., Simms, B., Hamming, K.S., Snutch, T.P., Mezeyova, J., McRory, J.E., Zamponi, G.W., 2004. Gating effects of mutations in the Cav3.2 T-type calcium channel associated with childhood absence epilepsy. J. Biol. Chem. 279(11), 9681-9684.

24. Lachance-Touchette, P., Brown, P., Meloche, C., Kinirons, P., Lapointe, L., Lacasse, H., Lortie, A., Carmant, L., Bedford, F., Bowie, D., Cossette, P., 2011. Novel $\alpha 1$ and $\gamma 2$ GABAA receptor subunit mutations in families with idiopathic generalized epilepsy. Eur. J. Neurosci. 34(2), 237-249.

25. Lachance-Touchette, P., Choudhury, M., Stoica, A., Di Cristo, G., Cossette, P., 2014. Single-cell genetic expression of mutant GABAA receptors causing Human genetic epilepsy alters dendritic spine and GABAergic bouton formation in a mutationspecific manner. Front. Cell Neurosci. 8, 317.

26. Merner, N.D., Chandler, M.R., Bourassa, C., Liang, B., Khanna, A.R., Dion, P., Rouleau, G.A., Kahle, K.T., 2015. Regulatory domain or CpG site variation in SLC12A5, encoding the chloride transporter $\mathrm{KCC} 2$, in human autism and schizophrenia. Front. Cell Neurosci. 9, 386.

27. Niturad, C.E., Lev, D., Kalscheuer, V.M., Charzewska, A., Schubert, J., Lerman-Sagie, T., Kroes, H.Y., Oegema, R.,
Traverso, M., Specchio, N., Lassota, M., Chelly, J., Bennett-Back, O., Carmi, N., Koffler-Brill, T., Iacomino, M., Trivisano, M., Capovilla, G., Striano, P., Nawara, M., Rzonca, S., Fischer, U., Bienek, M., Jensen, C., Hu, H., Thiele, H., Altmüller, J., Krause, R., May, P., Becker, F., EuroEPINOMICS Consortium, Balling, R., Biskup, S., Haas, S.A., Nürnberg, P., van Gassen, K.L.I., Lerche, H., Zara, F., Maljevic, S., Leshinsky-Silver, E., 2017. Rare GABRA3 variants are associated with epileptic seizures, encephalopathy, and dysmorphic features. Brain. 140(11), 28792894.

28. Rajakulendran, S., Hanna, M.G., 2016. The Role of Calcium Channels in Epilepsy. Cold Spring Harb. Perspect. Med. 6(1), 022723.

29. Rogers, M.F., Shihab, H.A., Mort, M., Cooper, D.N., Gaunt, T.R., Campbell C.2018. FATHMM-XF: Accurate prediction of pathogenic point mutations via extended features. Bioinformatics. 34(3), 511-513.

30. Saint-Martin, C., Gauvain, G., Teodorescu, G., Gourfinkel-An, I., Fedirko, E., Weber, Y.G., Maljevic, S., Ernst, J.P., GarciaOlivares, J., Fahlke, C., Nabbout, R., LeGuern, E., Lerche, H., Poncer, J.C., Depienne, C. 2009. Two novel CLCN2 mutations accelerating chloride channel deactivation are associated with idiopathic generalized epilepsy. Hum. Mutat. 30(3), 397-405.

31. Saito, T., Ishii, A., Sugai, K., Sasaki, M., Hirose, S., 2017. A de novo missense mutation in SLC12A5 found in a compound heterozygote patient with epilepsy of infancy with migrating focal seizures. Clin. Genet. 92(6), 654-658.

32. Scheffer, I.E., Berkovic, S., Capovilla, G., Connolly, M.B., French, J., Guilhoto, L., Hirsch, E., Jain, S., Mathern, G.W., Moshé, S.L., Nordli, D.R., Perucca, E., Tomson, T., Wiebe, S., Zhang, Y.H., Zuberi, S.M., 2017. ILAE classification of the epilepsies: position paper of the ilae commission for classification and terminology. Epilepsia. 58(4), 512-521.

33. Stafstrom, C.E., Carmant, L., 2015. Seizures and epilepsy: an overview for neuroscientists. Cold Spring Harb. Perspect. Med. 5(6), a022426.

34. Stogmann, E., Lichtner, P., Baumgartner, C., Bonelli, S., AssemHilger, E., Leutmezer, F., Schmied, M., Hotzy, C., Strom, T.M., Meitinger, T., Zimprich, F., Zimprich, A. 2006. Idiopathic generalized epilepsy phenotypes associated with different EFHC1 mutations. Neurology. 67(11), 2029-2031.

35. Suzuki, T., Delgado-Escueta, A.V., Aguan, K., Alonso, M.E., Shi, J., Hara, Y., Nishida, M., Numata, T., Medina, M.T., Takeuchi, T., Morita, R., Bai, D., Ganesh, S., Sugimoto, Y., Inazawa, J., Bailey, J.N., Ochoa, A., Jara-Prado, A., Rasmussen, A., Ramos-Peek, J., Cordova, S., Rubio-Donnadieu, F., Inoue, Y., Osawa, M., Kaneko, S., Oguni, H., Mori, Y., Yamakawa, K., 2004. Mutations in EFHC1 cause juvenile myoclonic epilepsy. Nat. Genet. 36(8), 842-849.

36. Venselaar, H., Te Beek, T.A., Kuipers, R.K., Hekkelman, M.L., Vriend, 2010. Protein structure analysis of mutations causing inheritable diseases. An e-Science approach with life scientist friendly interfaces. BMC Bioinformatics. 11, 548.

37. Zoons, E., Weisfelt, M., de Gans J., Spanjaard, L., Koelman, J.H., Reitsma, J.B., van de Beek, D., 2008. Seizures in adults with bacterial meningitis. Neurology. 70(22 Pt 2), 2109-2115. 